\title{
Persistent dextrocardia after adult orthotopic heart transplantation in a patient with complex congenital heart disease
}

Nicola Pradegan, MD, Gino Gerosa, MD, Maurizio Rubino, MD, and Giuseppe Toscano, MD, Padova, Italy

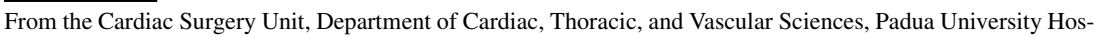
pital, Padova, Italy.

Disclosures: Authors have nothing to disclose with regard to commercial support.

Received for publication Sept 4, 2018; revisions received Oct 21, 2018; accepted for publication Nov 4, 2018 ; available ahead of print Dec 7, 2018.

Address for reprints: Gino Gerosa, MD, Cardiac Surgery Unit, Department of Cardiac, Thoracic, and Vascular Sciences, University of Padua, Via Giustiniani 2, 35128 Padova, Italy (E-mail: gino.gerosa@unipd.it).

J Thorac Cardiovasc Surg 2019; 157:e271-2

$0022-5223 / \$ 36.00$

Copyright (c) 2018 by The American Association for Thoracic Surgery

https://doi.org/10.1016/j.jtcvs.2018.11.019
}

- Video clip is available online.

Dextrocardia is still a surgical challenge for patients requiring heart transplantation. Finding a donor with dextrocardia is virtually impossible. There are few recent cases reports of heart transplantation in patients with dextrocardia, ${ }^{1-3}$ none considering the possibility of leaving long recipient vessel segments to place the heart into the right chest cavity left by the explanted heart.

\section{CLINICAL SUMMARY}

We report the case of a 44-year-old woman with dextrocardia and associated complex congenital heart defects: double-inlet left ventricle with right ventricular accessory outflow chamber, double-outlet from the outflow chamber, and pulmonary stenosis. Because of worsening cyanosis during childhood, a left BlalockTaussig shunt was created. At age 40 years she began to develop progressive shortness of breath and symptomatic tachyarrhythmias. Despite optimal medical therapy, she did not improve and due to worsening of clinical conditions the patient was finally listed for heart transplantation.

The preoperative anatomy was characterized by bilateral superior venae cavae and a right inferior vena cava connected to the common atrium. The 4 pulmonary veins drained into the common atrium through a single orifice. The left ventricle was right-sided and posterior with a left-sided and anterior accessory outflow chamber from which arose the side-by-side great arteries (Figure 1). after transplantation.

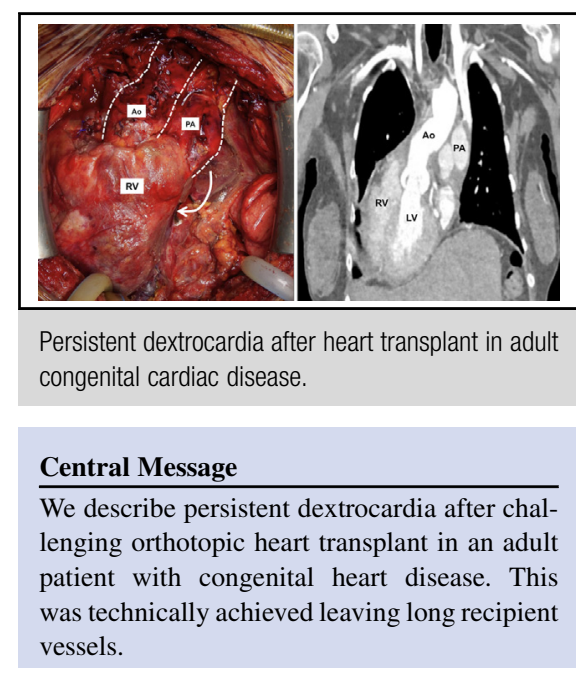

See Commentary page e275.

The heart was approached through a longitudinal sternotomy and bicaval-aortic cardiopulmonary bypass was instituted. After cardiectomy, 2 separate atria were constructed directing caval flow to the right-sided atrium and pulmonary venous blood to the left-sided atrium. The donor heart (that had been explanted in a conventional fashion) was connected using bilateral atrioatrial and arterial anastomoses. Despite left pleural space opening, the heart was then rotated clockwise about $90^{\circ}$ to fit into the space left by the explanted heart and to facilitate chest closure: long recipient aortic and pulmonary trunk segments were anastomized to the correspondent part of the donor graft. The final result was a dextrocardia-like appearance of the new heart (Figure 2, $A$ and $B$ ).

Mechanical circulatory support was required for the first 5 postoperative days because of temporary biventricular dysfunction due to long cardiopulmonary bypass $(310 \mathrm{mi}-$ nutes). No clinical or echocardiographic signs of tamponade and inflow stenosis were detected during the postoperative course. Recurrent left pleural effusions required multiple drainage procedures and prolonged mechanical ventilation necessitating temporary tracheostomy. The patient was discharged to a rehabilitation center in good clinical status and was weaned from tracheostomy 3 months 


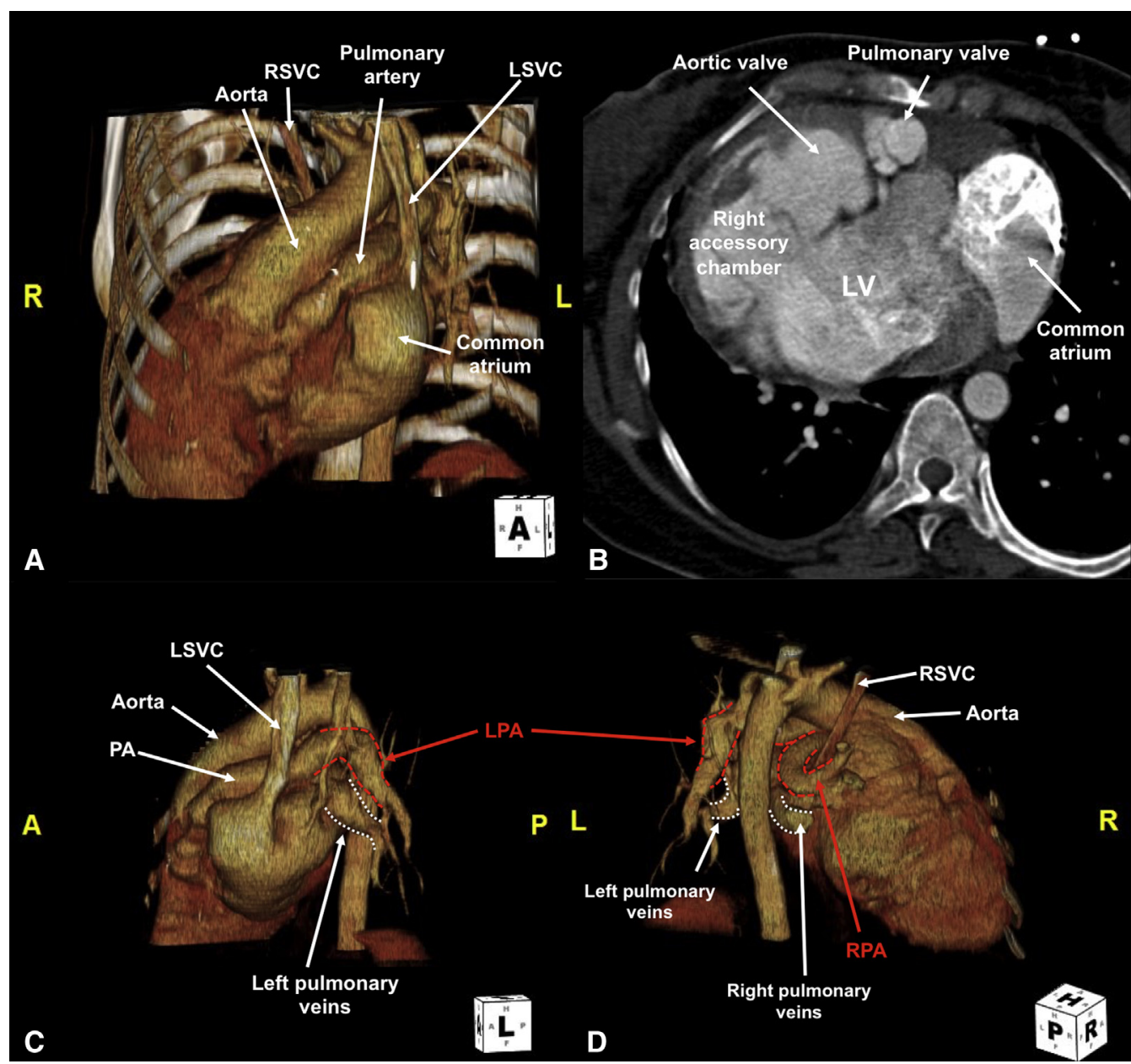

FIGURE 1. A, Preoperative cardiac computed tomography scan showing double inlet left ventricle with right ventricular accessory outflow chamber, with double-outlet from the outflow chamber. A, 3-dimensional (3D) reconstruction. B, Axial plane. $R S V C$, Right superior vena cava; $L S V C$, left superior vena cava; $R$, right side; $L$, left side; $A$, anterior aspect; $L V$, left ventricle. C, $3 \mathrm{D}$ reconstruction of the left cardiac posterior aspect. $\mathrm{D}, 3 \mathrm{D}$ reconstruction of the cardiac posterior aspect. These better show 2 not communicating superior venae cavae and normal pulmonary vessels. $A$, Anterior side; $P A$, pulmonary artery; $P$, posterior side; $R P A$, right pulmonary artery; $H$, head side.

\section{DISCUSSION}

Our case highlights that preoperative dextrocardia in adult patients with congenital heart disease does not limit heart transplantation with a normal donor heart. Venous and arterial anastomoses can be performed without major manipulation of the graft by reconstructing or augmenting the recipient atria and leaving long recipient arterial segments. The donor heart can be located on the right chest without diastolic dysfunction or torsion of venous or arterial connections avoiding opening the left pleural space and partial left lung resection (Figure 2, C1-C3).

To the best of our knowledge, this is the first reported case of orthotopic heart transplantation in an adult patient with complex congenital heart disease and dextrocardia that was successfully performed maintaining the normal donor heart in the original position without hemodynamic impairment (Video 1).

The authors thank Dr S. P. Sanders, Boston Children's Hospital, Boston, Mass, for reviewing the manuscript.

\section{References}

1. Uoc NH, Quan PT. Heart transplant for dextrocardia situs inversus with very complex congenital lesions: a challenge of cardiac surgery. Int J Clin Cardiol. 2015;2: 49.

2. Deuse T, Reitz BA. Heart transplantation in situs inversus totalis. J Thorac Cardiovasc Surg. 2010;139:501-3.

3. Tector AJ, Savitt M, Dankle CJ, Downey FX, Levin J, Nelson R, et al. Orthotopic heart transplantation in a patient with corrected L-transposition of great arteries and dextrocardia. J Heart Lung Transplant. 2008;27:1362-3. 

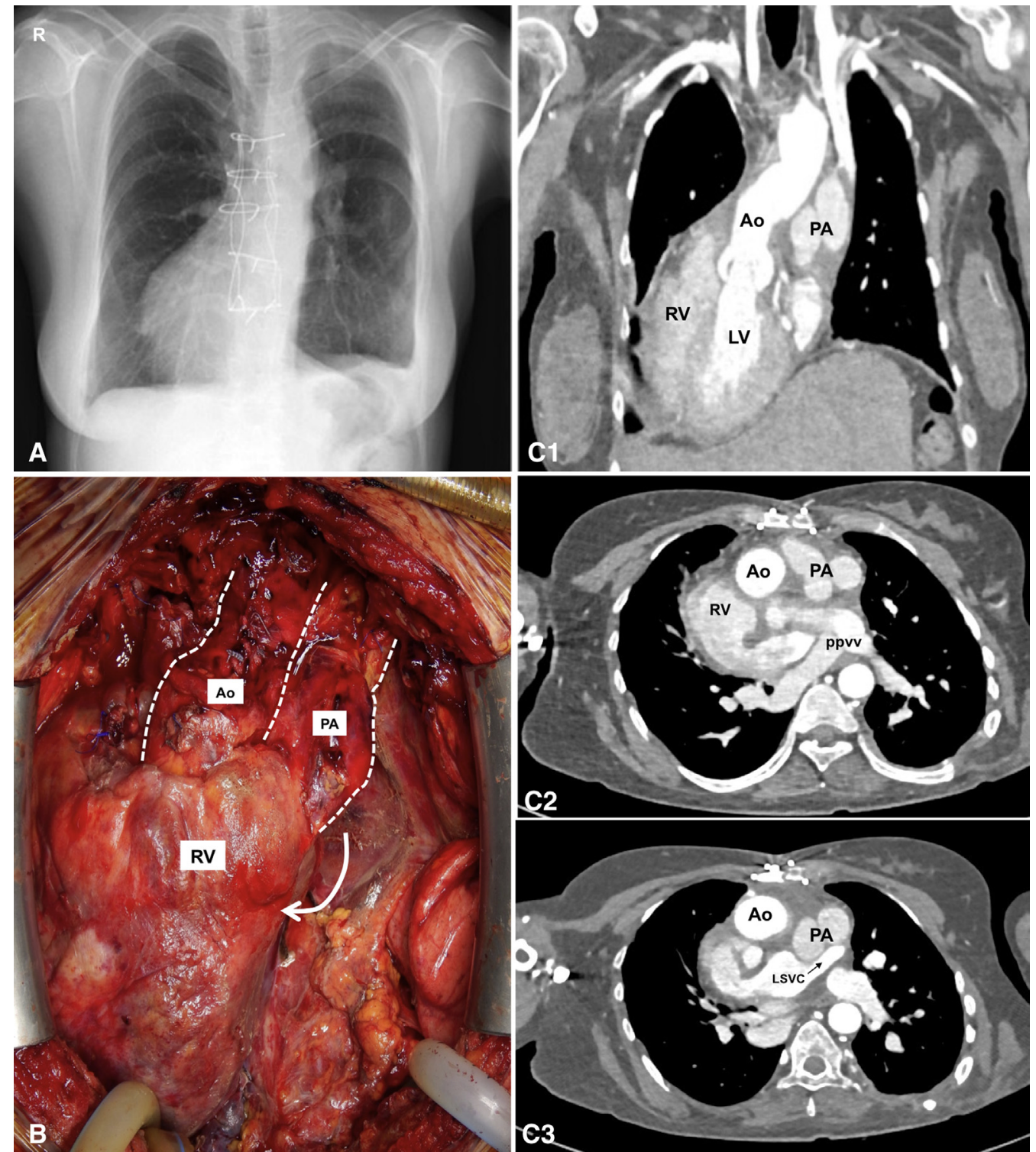

FIGURE 2. Postoperative anatomy of the transplanted heart. A, Chest radiography at discharge. B, Intraoperative cardiac anatomy. C1, Postoperative coronal computed tomography (CT) scan plane. C2 and C3, Axial cardiac CT-scan planes. These show the absence of residual torsion or kinking among the arterial and the venous vessels. Curved arrow indicates heart clockwise rotation. $R$, right side; $A o$, ascending aorta; $P A$, pulmonary artery; $R V$, right ventricle; $L V$, left ventricle; $p p v v$, pulmonary veins; $L S V C$, left superior vena cava.

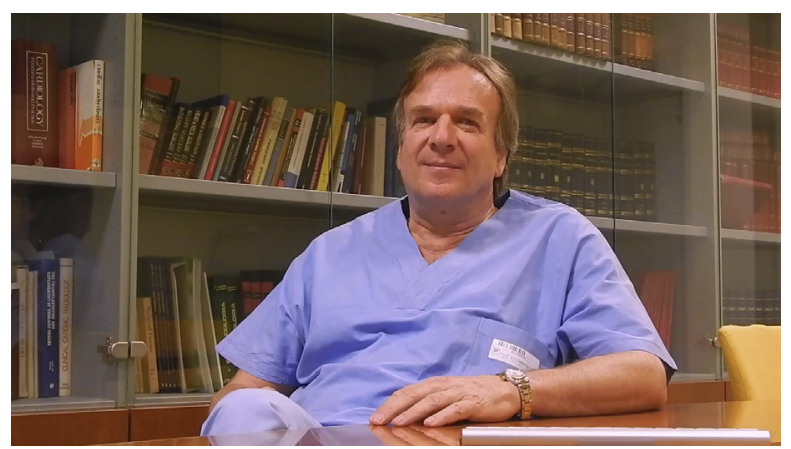

VIDEO 1. One of the authors (G.G.) presenting the surgical case and its relevance. Video available at: https://www.jtcvs.org/article/S0022-5223 (18)32966-0/fulltext. 